\title{
CBT for OCD: habituation or cognitive shift?
}

\author{
Lottie Morris $^{1 *}$ and Jim Nightingale ${ }^{2}$ \\ ${ }^{1}$ Department of Psychology, 6W 0.9, University of Bath, Claverton Down, Bath, UK \\ ${ }^{2}$ Psychological Therapies Service, Cedar House, Blackberry Hill Hospital, Manor Road, Fishponds, \\ Bristol, UK
}

Received 30 July 2013; Accepted 11 April 2014

\begin{abstract}
Cognitive Behavioural Therapy (CBT) including Exposure and Response Prevention (ERP) is recommended by NICE as the psychological treatment of choice for obsessive compulsive disorder (OCD). Twenty-five percent of OCD patients refuse ERP, and many psychologists advocate formulation-driven cognitive therapy, including ERP, as opposed to ERP alone. However, a recent meta-analysis suggested there is insufficient evidence to suggest ERP is improved by cognitive methods. This paper proposes to contribute to this debate by providing a detailed description of the treatment of a patient with intrusive cognitions of a sexual nature, who was treated successfully using behavioural experiments designed to test cognitions, rather than ERP. This is, arguably, the way in which most cognitive behavioural therapists would work with someone with OCD. However, this approach is not reflected in the literature at present. The authors report the patient's feedback that therapeutic change was brought about through cognitive shift, as a result of the formulation-driven behavioural experiments.
\end{abstract}

Key words: Behavioural cognitive therapy, belief modification, CBT, cognition, OCD.

\section{Theoretical and research basis for therapy}

This paper begins by reviewing pertinent literature relating to this case. Anna's presenting problem is then described, along with the cognitive behavioural hypotheses developed during treatment. The process and outcomes of treatment are outlined, and the paper then focuses on exploring the patient's views of which aspects of therapy were the most important factors in stimulating change.

\section{Literature review}

Obsessive compulsive disorder (OCD) is characterized by persistent, intrusive cognitions, and/or compulsive behaviours (DSM-IV-TR; APA, 2000). OCD can be a debilitating, longterm disorder, if left untreated. The efficacy of CBT approaches for OCD has been well established in highly controlled clinical settings (e.g. NICE, 2005; Ponniah et al. 2013) and in

\footnotetext{
*Author for correspondence: L. Morris, Department of Psychology, 6W 0.9, University of Bath, Claverton Down, Bath BA2 7AY, UK (email: lottie.morris@nhs.net)
} 
community mental health settings (Drummond et al. 2008). It remains the case that CBT does not work for all patients due to variables including the therapy process (Polman et al. 2010), and the refusal of exposure and response prevention (ERP) and associated drop-out (Foa et al. 2005). Therefore it is important to share findings from individual case studies to contribute to the understanding of which aspects of the therapy process are likely to contribute to successful outcomes for patients.

\section{The nature of $\mathrm{OCD}$}

It is hypothesized by many contemporary psychologists (e.g. Salkovskis, 1985, 1989; Rachman, 1997, 1998; Wells, 1997, 2000) that OCD develops when internal experiences encountered by most of the general population at times (Rachman \& DeSilva, 1978), such as thoughts (e.g. wishing harm on someone) and urges (e.g. the urge to jump off a cliff when you are standing at the edge) are misinterpreted in a negative way, activating dysfunctional beliefs about the meaning of the thought or urge. These beliefs, in turn, affect the person's behaviour and emotions. These beliefs bring about uncomfortable emotions, and the person normally engages in a number of compensatory behaviours to neutralize the perceived consequences of the misinterpreted thought. Paradoxically, these behaviours often maintain or exacerbate the intrusion, so it becomes an obsession. The person then feels compelled to keep engaging in perceived neutralizing behaviours, and so the cycle continues - perhaps a key reason why OCD tends to have such a chronic course, if untreated. The neutralizing behaviours do often succeed at reducing anxiety in the short-term; however, they tend to prevent disconfirmation of the interpretation of the intrusion and its perceived consequences (Rachman, 1997). For example, for someone with a fear of contaminating others, hand-washing would provide temporary anxiety relief, but in the long-term, would prevent the individual from discovering that their unwashed hands do not cause illness or death to others, thus maintaining the problem.

The nature of OCD is different for each individual; however, there are some commonalities which are apparent in most cases. While a range of cognitive models of OCD exist, the Obsessive Compulsive Cognitions Working Group (OCCWG, 1997) identified several types of dysfunctional belief that seem generally to be implicated in the development and maintenance of OCD: overestimation of threat; intolerance of uncertainty; perfectionism; overestimation of the importance of thoughts; overestimation of responsibility; and overestimation of the importance of controlling one's thoughts. Additionally, the OCCWG identified that latter three of these beliefs are common interpretations of intrusive images/thoughts/urges in OCD.

In Anna's case, overestimation of responsibility, threat, importance of thoughts, and importance of controlling thoughts were apparent. This is described in more detail later on.

\section{Current debates in OCD treatment: ERP vs. formulation-driven CBT}

Behavioural theories of OCD propose that safety-seeking behaviours occur when they are successful at reducing anxiety in stressful situations (e.g. when an intrusive thought occurs). By reducing anxiety, these behaviours are strengthened through negative reinforcement. Traditionally, ERP is based on the behavioural premise that, if an individual is exposed to situations that provoke anxiety and intrusive thoughts, but prevented from escaping or using the usual safety-seeking behaviours, the anxiety will decrease over time, so eventually the 
patient will habituate to the feared response and be able to return to normal functioning (Dollard \& Miller, 1950). In contrast, behavioural experiments are designed explicitly to test cognitions, and, while they often involve some level of exposure, this is not always the case (surveys are an example of this). In summary:

- ERP involves repeated, prolonged exposure to a feared stimulus, without using safetyseeking behaviours. In its purest form, cognitions are not elicited, and it is not necessary to ask the client what they have learnt from the exposure; whereas

- behavioural experiments are designed to test cognitions.

Clearly there will frequently be overlap in these two methods during therapy: Ponniah et al. (2013) make a distinction between therapy procedures and underlying mechanisms. For example, while ERP and behavioural experiments might both provide exposure to a feared stimulus, according to behavioural theory, the underlying mechanism of both procedures is habituation, whereas according to cognitive theory, both procedures would facilitate cognitive shift through providing disconfirmatory evidence of the belief under scrutiny.

A recent systematic review and meta-analysis by Jonsson \& Hougaard (2009) states that the psychological treatment with the most empirical evidence is ERP, citing NICE (2005) guidelines and a meta-analytical review by Abramowitz et al. (2002). Furthermore, the authors state that there is no evidence that supplementing ERP with cognitive methods achieves better results than ERP alone. However, it is estimated that around $25 \%$ of patients drop out from or refuse ERP (Franklin \& Foa, 1998; Foa et al. 2005), and some studies propose that this treatment would be improved by incorporating cognitive methods (Wilhelm, 2001; Radomsky et al. 2010). Rachman (2003), among many others, advocates a formulation-driven approach to OCD, rather than a one size fits all attitude.

It is important to note that, although ERP is recommended, there is a prevailing view among clinicians and researchers that few therapists today use ERP in its traditional form (based on habituation) (Shafran et al. 2013), although there are no data to support or refute this. Rather, Shafran and colleagues suggest that most therapists probably use ERP in the context of psycho-education, and behavioural experiments designed to test cognitions. Nonetheless, if this is the case, perhaps guidelines should reflect this because, at present, they recommend ERP.

The present study reports a the case of a woman (Anna) seen within an Improving Access to Psychological Therapies (IAPT) service, where OCD symptoms were successfully ameliorated using a number of behavioural experiments designed to test cognitions, although some did include elements of exposure. The present paper seeks to add to the OCD treatment debate by exploring the patient's and therapist's views of which aspects of CBT were most effective in improving the patient's OCD symptoms and overall quality of life.

\section{Case assessment}

The following questionnaires were used to assess general impact of therapy:

- The diagnosis and severity of OCD was assessed at weeks 1 and 14 using the Obsessive Compulsive Inventory (OCI; Foa et al. 1998). The OCI is reported as having good to excellent internal consistency, test-retest reliability, and discriminant validity (Foa et al. 1998). 
- Depressive symptoms were assessed on a weekly basis using the Patient Health Questionnaire - 9 (PHQ-9), which is reported as a reliable and valid diagnostic measure of depression severity (Kroenke et al. 2001)

- Anxiety symptoms were assessed on a weekly basis using the Generalized Anxiety Disorder Assessment - 7 (GAD-7), a valid and efficient tool for screening GAD and assessing its severity (Spitzer et al. 2006)

- Avoidance was assessed on a weekly basis using the IAPT Phobia Scales, which are used routinely by IAPT services across the UK. A literature search was unable to determine reliability and validity.

- The impact of OCD symptoms on work and social adjustment was assessed using the IAPT Work and Social Adjustment Scales (Marks, 1986), a sensitive, reliable, and valid tool (Mundt et al. 2002)

The following questionnaires were completed by Anna 3 weeks after therapy to assess her views of the therapy process:

- Qualitative information about therapy process was yielded using the Helpful Aspects of Therapy Questionnaire, which was explored quantitatively using the Event Impact Ratings Scale (Llewelyn, 1988). It was unclear from the literature whether reliability and validity of this measure had been established; however, it was chosen as it provided useful prompting questions to elicit Anna's perceptions of therapy.

The therapeutic alliance was also measured quantitatively using the Working Alliance Inventory, which has been found to have good reliability and validity (Horvarth \& Greenberg, 1989). Therapeutic alliance is widely believed to be associated with good psychotherapy outcomes (Martin et al. 2000), so it was important to measure this as a potential active component in therapy. However, we cannot infer that this association is causal.

\section{Case summary and presenting problem}

Anna was referred to an IAPT service by her GP. Anna had been experiencing distressing intrusive thoughts and urges for the last $5 \frac{1}{2}$ years. Anna experienced regular urges to look at other people's chests and groins, and believed that other people noticed this and made negative judgements about her. These intrusions had a significant impact on Anna's life: she had withdrawn from socializing and felt stuck in a job she did not have the confidence to leave, due to her intrusive thoughts. During assessment, Anna reported that she had spent over $£ 1000$ on private treatments for this problem, including hypnotherapy, meditation, and person-centred counselling. None of these treatments had been successful. Prior to individual CBT, Anna had completed a 4-week CBT for anxiety group, which she reported had not affected her OCD symptoms.

\section{Formulation}

Through discussion, Anna and the therapist collaboratively developed a theory of how the problem developed and what had been maintaining it. This theory corresponded well with the cognitive behavioural maintenance model of OCD proposed by Salkovskis (1985) and Wells (1997), so this was shared with Anna as a way to understand the problem. Alternative 
theoretical frameworks were not considered at great length, as meta-analyses suggest that CBT as the first-line treatment of choice for people with OCD (e.g. NICE, 2005).

Anna had experienced a difficult childhood: during early adolescence, her stepfather made repeated sexual advances towards her, and her mother allowed this to occur. Anna reported that her mother was also very critical and unloving. Despite these adversities, Anna left home at a young age and led a successful life, although she described her self-esteem and confidence in social situations as always having been low.

It was hypothesized that years of fearing unwanted sexual advances had led Anna to believe that looking at others' chests or crotches was dangerous. Anna believed that she looked excessively at these areas, and it was agreed that this could be either a misinterpretation, or because her past experiences made her more likely to look at these areas as Darwinian threat-detection behaviour (Darwin, 1955; LeDoux, 1998). Experiencing emotional abuse throughout childhood led Anna to think that others would make negative judgements about her behaviour. Because of these two factors, when Anna first noticed herself looking at someone else's chest, her first thoughts were, 'they must have noticed'; 'it will have upset them'; 'they will judge me negatively'; and 'this is really inappropriate (dangerous) behaviour'. Many people experience similar intrusive thoughts and urges of a sexual nature (Rachman \& DeSilva, 1978). However, because this was perceived as dangerous to Anna due to her past sexual and emotional abuse experiences, she then engaged in a number of safety-seeking behaviours, including avoidance, hypervigilance, and self-monitoring, which prevented her from finding out that her interpretations were inaccurate, and worsened the problem (Clark, 1986; Salkovskis, 1991).

Anna's safety-seeking behaviours were behavioural: avoidance of social situations, distracting others with jokes, not making eye contact, blocking her line of vision, screwing up her eyes; and cognitive: inwardly focused attention and self-monitoring [known to heighten social anxiety (Clark \& Wells, 1995)], hypervigilance for negative responses from others, and thought suppression [thought, paradoxically, to increase the unwanted thought (Wegner et al. 1987), although this finding has been inconsistent across studies (e.g. Purdon, 2004)]. By trying not to think of or look at others' groins/chests, this made the intrusion occur more often, thus noticing thoughts about looking at someone else's chest quickly turned into an urge. Anna believed that others could sense that she felt this compulsion [an example of thought-object fusion (Wells, 1997, 2000)].

Anna also predicted that, when she experienced thoughts about looking at other people's chests/groins, her eyes would become 'stuck' on their chest/groin, unless she used safetyseeking behaviours to cope [an example of thought-action fusion (Wells, 1997, 2000)]. Anna and the therapist agreed that the behavioural safety-seeking behaviours may have been altering people's reactions to her, which she would misinterpret as evidence that they had noticed and were upset by her looking at their chest/groin.

Based on this formulation, Anna and the therapist collaboratively agreed some testable hypotheses (type of dysfunctional belief, as identified by OCCWG, given in parentheses):

(i) Looking at or having an urge to look at others' chests/groins is unusual (overestimation of the importance of one's thoughts).

(ii) Anna looks excessively at others' chests/groins (overestimation of the importance of one's thoughts). 


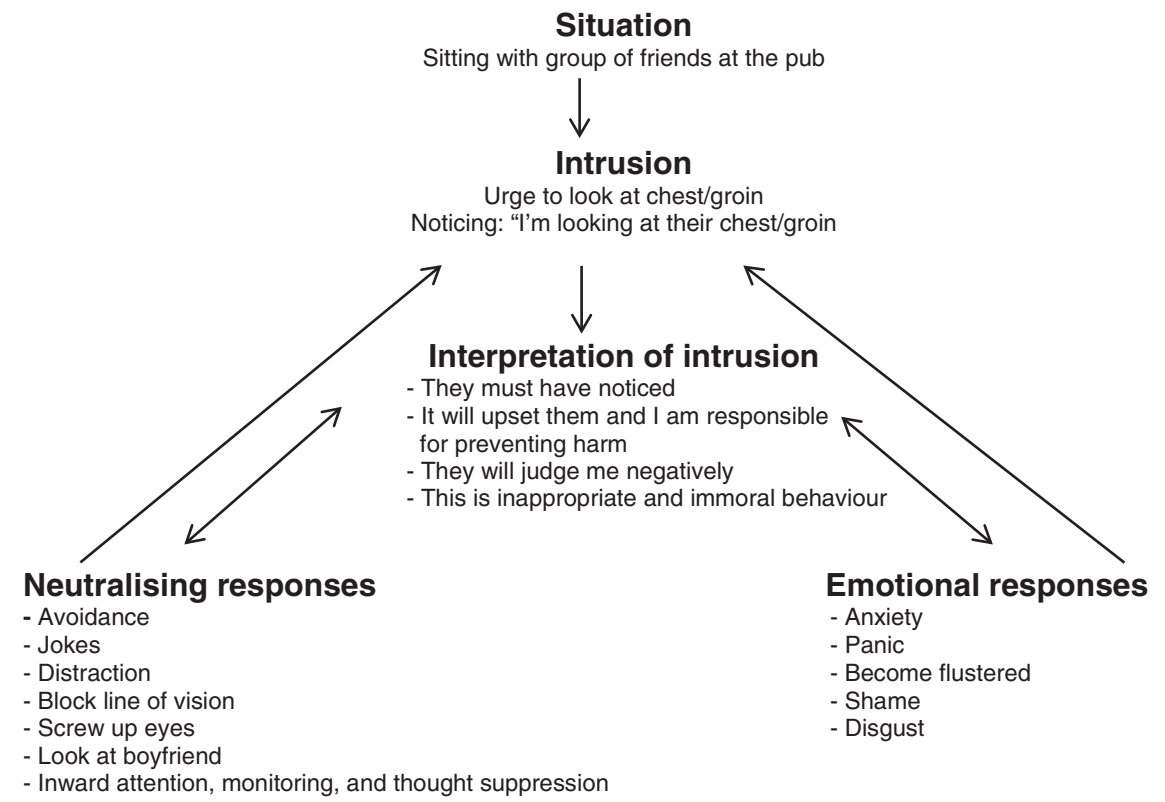

Fig. 1. Diagram of formulation used in therapy, based on a simplified amalgamation of Wells (1997) and Salkovskis (1985).

(iii) If Anna drops the safety-seeking behaviours during social interaction, her eyes will become 'stuck' on the other person's chest/groin (overestimation of threat, the importance of thoughts, and the importance of controlling one's thoughts).

(iv) Other people notice Anna looking at their chest/groin (overestimation of threat, responsibility, and the importance of thoughts).

(v) Other people are upset by this (overestimation of responsibility).

(vi) Other people make negative judgements about Anna looking at their chest/groin (overestimation of threat and responsibility).

(vii) Anna's safety-seeking behaviours make her seem shy or odd.

(viii) Trying not to look at chests/groins makes the urge stronger.

(ix) Inward attention increases anxiety and the intrusive thoughts.

The formulation used in therapy is illustrated in diagrammatic format in Figure 1.

\section{Intervention}

\section{Therapist details and supervisory arrangements}

The therapist was a trainee clinical psychologist in her first year of training, supervised weekly by an experienced, BABCP-accredited clinical psychologist.

\section{Course of therapy and behavioural experiments}

In order to promote optimal outcome (Keijsers et al. 2000), the therapeutic relationship was developed from the initial session, using basic Rogerian (Rogers, 1957) principles. 
Socialization to the cognitive behavioural model (Daniels \& Wearden, 2011) was also encouraged using psycho-education and a collaborative approach. The hypotheses outlined above were discussed at length during therapy using Socratic dialogue and guided discovery, and the above formulation developed collaboratively. The hypotheses were weighed up by setting out the evidence for and against each idea. In the initial assessment session, Anna was $100 \%$ convinced that other people noticed her looking at their chest/groin, and were offended by it. Once doubts about this belief had been raised through sensitive discussion, a number of behavioural experiments were devised collaboratively to test each hypothesis (see Table 1).

These behavioural experiments were undertaken at a pace and level suitable to Anna's belief in her original hypotheses (i)-(vi). Anna was able to engage in some difficult tasks because she quickly understood the purpose and made sense of them within her individualized formulation. The experiments increased in perceived difficulty as Anna's conviction in her negative interpretations of the intrusive thought reduced: for instance, an early experiment was talking to her sister about whether she had ever noticed Anna looking at her chest, and one of the final experiments was going to the gym and striking up conversations with people in the jacuzzi - a situation which would have been feared previously and avoided as the perceived risk of eyes becoming 'stuck' and causing offence increased in situations where others were wearing revealing clothing.

Over time, the cumulative results of these tasks led Anna to discover that: her interpretations about her intrusive thoughts/urges and other people's reactions were inaccurate; and that her safety-seeking behaviours were worsening the problem. By the end of therapy, Anna reported that she was experiencing periods while socializing, where she was completely engaged in the situation and not thinking at all about where to look. Overcoming this problem meant Anna was able to begin to re-build her social life, and make changes to aspects of her personal and work life that she was not happy with.

\section{Follow-up}

\section{Therapy outcome measures}

The OCI was completed at weeks 1 and 8 of therapy, and again at 3 weeks post-therapy (Fig. 2). Scores reduced from clinical (total $\geq 40$ ) to non-clinical during therapy, and change was maintained at 3 weeks after therapy.

Trends of improvement were also seen in the PHQ-9 (reduced from 8 to 2), GAD-7 (reduced from 8 to 0), IAPT Phobia Scales (reduced from 12 to 2), and IAPT Work and Social Adjustment Scales (reduced from 10 to 4) (see Appendix), although Anna acknowledged in the Helpful Aspects of Therapy Questionnaire that these ratings were affected by adverse life events which occurred during therapy.

\section{Therapy process measures}

In order to assess which had been the most helpful aspects of therapy, from the patient's viewpoint, process questionnaires were completed by the patient and returned by post. The findings are outlined below.

The Helpful Aspects of Therapy Questionnaire was administered. Anna outlined that the tasks aimed at challenging her cognitions were the most helpful aspects of therapy: 
Table 1. Behavioural experiments designed to test Anna's hypotheses

\begin{tabular}{|c|c|}
\hline Behavioural experiment & Hypotheses tested \\
\hline Questioning others to test beliefs/interpretations & i, ii, iv, v, vi, vii \\
\hline \multicolumn{2}{|l|}{$\begin{array}{l}\text { Anna asked a number of trusted relatives and colleagues, whom she } \\
\text { thought had noticed and been upset by her looking excessively at their } \\
\text { chest/groin, whether they had noticed. No-one reported noticing or being } \\
\text { upset; however, some had noticed Anna's lack of eye contact. }\end{array}$} \\
\hline Survey method & $\mathrm{i}$, ii, iv, v, vi \\
\hline \multicolumn{2}{|l|}{$\begin{array}{l}\text { A questionnaire to the general public was co-designed by Anna and the } \\
\text { therapist to find out how often other people experience similar thoughts } \\
\text { or urges, and what they would think if they noticed someone glance at } \\
\text { their chest/groin (e.g. Have you ever noticed accidentally glancing at } \\
\text { someone else's chest/groin?) }\end{array}$} \\
\hline Examining evidence & i, ii \\
\hline \multicolumn{2}{|l|}{$\begin{array}{l}\text { The therapist shared with Anna results from a study of eye gaze tracking in } \\
\text { men and women, which showed that the groin and chest featured in } \\
\text { other people's eye gaze patterns (Cornelissen } \text { et al. 2009) }\end{array}$} \\
\hline Specifically testing predictions by interrogating the environment & iii, iv, v, viii \\
\hline \multicolumn{2}{|l|}{$\begin{array}{l}\text { Anna and the therapist agreed a task where Anna interacted with shop } \\
\text { assistants in a department store, using three conditions: (1) Using usual } \\
\text { safety-seeking behaviours; (2) deliberately glancing five times at chest } \\
\text { or groin during conversation; and (3) dropping all safety-seeking } \\
\text { behaviours. Anna found that her prediction that her eyes would become } \\
\text { 'stuck' in conditions (2) and (3) did not happen. }\end{array}$} \\
\hline Using video feedback to examine interpretations and perceptions & ii, iii, iv, v, vii, viii \\
\hline \multicolumn{2}{|l|}{$\begin{array}{l}\text { The above experiment was covertly video-recorded (with Anna's } \\
\text { permission). Anna had thought that, in condition (2), the shop assistant } \\
\text { had given her a funny look. On reviewing the video, Anna observed that } \\
\text { this had not happened, which made her question her interpretation of } \\
\text { others' facial expressions. Anna also observed that she looked 'frantic' } \\
\text { in condition (1), and more relaxed in conditions (2) and (3). }\end{array}$} \\
\hline Exploring utility of safety-seeking behaviours & iii, iv, viii, ix \\
\hline $\begin{array}{l}\text { Anna engaged regularly in tasks between sessions to explore how useful } \\
\text { her safety-seeking behaviours were, and whether negative predictions } \\
\text { came true when these behaviours were not undertaken. For example, one } \\
\text { week, Anna alternated daily between self-focused and other-focused } \\
\text { attention. Anna predicted that moving attention from internal } \\
\text { (self-monitoring to prevent looking at others' chests/groins) to external } \\
\text { would make the feared event happen, but found that she was more } \\
\text { relaxed, enjoyed socializing more, and started to experience periods } \\
\text { where the intrusion/urge was completely absent. }\end{array}$ & \\
\hline
\end{tabular}




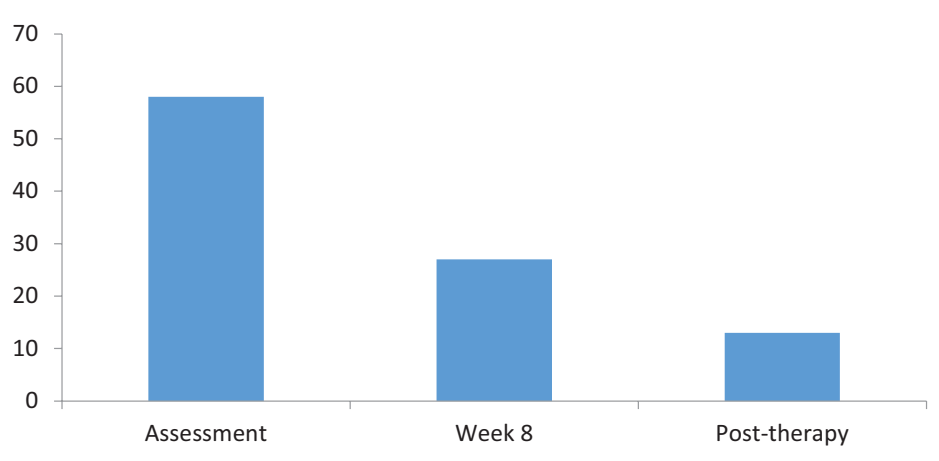

Fig. 2. Graph of Anna's Obsessive Compulsive Inventory scores at weeks 1, 8, and 3 weeks post-therapy (week 17).

The patient rated this event as very helpful in making a highly positive contribution to: personal insight; problem clarification; understanding about others; increases in understanding; reassurance; sense of relief; involvement in therapy; personal contact with the therapist; safe expression of distress; and being listened to.

Overall, Anna reported that the following features of therapy were most beneficial:

Practical focus; exercises aimed at challenging perceptions; model highlights cycle of anxiety.

Realization that others weren't aware of my urge to glance and my anxiety in general. Initially I was convinced that my interpretation of events was accurate. I now know this is not always the case.

Anna's final comments in the Helpful Aspects of Therapy Questionnaire demonstrate how treating her intrusive thoughts had a secondary benefit, of increasing her confidence, which had a positive impact on her life:

One of the most useful experiences making a huge positive impact on my life. I feel confident to regain control of my life and [illegible] to create the life I want.

\section{Client ratings of working alliance}

The patient reported good ratings of working alliance in the Helpful Aspects of Therapy Questionnaire and the Working Alliance Inventory (Appendix Table A1). As outlined earlier, alliance was assessed as a potential confounding variable, however Anna's self-report of the most helpful aspects of therapy suggests that successful outcome was due to changing her perceptions and interpretations, rather than alliance. 


\section{Limitations}

The present study has some obvious limitations. It would have been preferable to ask Anna to complete the OCI and a measure of cognitive change on a weekly basis; however, the therapist believed that this, in addition to the IAPT minimum dataset, might have been burdensome (although with hindsight, the therapist should have tested their own cognitions about this by asking Anna). Additionally, the mechanism of change was assessed using self-report: Anna perceived that the behavioural experiments promoted cognitive change; however, it would require a more sophisticated experimental methodology to prove this. Finally, this paper does not describe a novel intervention. Rather, it describes in detail an intervention style which is commonly used in the treatment of OCD, but which, the authors believe, is misrepresented in the literature when described as ERP.

\section{Therapy implications of the case}

The primary focus of the present paper is to add evidence to the debate around treatment of OCD: is it truly the case, as Abramowitz and colleagues (2002) argue, that supplementing ERP with cognitive methods is unnecessary? Or, is a formulation-driven approach, incorporating a person-centred range of cognitive change methods preferable, as advocated by several prominent authors (Wilhelm, 2001; Rachman, 2003; Radomsky et al. 2010)? The results of this study suggest that, from the patient's viewpoint, change was due to a range of behavioural experiments designed to test specific cognitive hypotheses identified by Anna with the therapist's assistance. The mechanism of change in this case appears to have been Anna's discovery that her perceptions and interpretations were inaccurate. There is no indication from Anna's self-report, or the content of therapy, that the mechanism for change was ERP and subsequent habituation to stressful situations.

\section{Cognitive methods as the active component of $C B T$ for $O C D$}

Anna reported that the video exercise was the most helpful aspect of therapy. She described how the active component of the exercise was receiving video feedback of the discrepancies between her interpretation of events, and reality. This method promoted a cognitive change: Anna's realization that her interpretations of events are sometimes inaccurate, and gave an alternative to her internalized self-image.

Anna also states that the 'realization that others weren't aware of my urge to glance' was helpful. Anna gathered this evidence early on in therapy, by asking trusted relations and colleagues whether they were aware of her problem, and using the survey method. It is highly likely that this too, contributed to Anna's cognitive shifts, which eventually led to the amelioration of her OCD symptoms.

It seems that the behavioural experiments were important to Anna in addressing the misinterpretations (and associated neutralizing behaviours) maintaining the problem. Overestimation of responsibility (e.g. 'I will offend other people'), threat (e.g. 'others will make negative judgements about me'), the importance of one's thoughts (e.g. 'if I think about chests I will look at them'), and the importance of controlling one's thoughts (e.g. 'unless I focus on not looking at chests, the urge to look will overcome me') were all explored and changed using behavioural experiments and discussion. 


\section{Collaborative, individualized formulation}

Anna reported in the Helpful Aspects of Therapy Questionnaire that the shared maintenance formulation (noting longitudinal influences) was helpful in understanding the cyclical nature of the problem: 'model highlights cycle of anxiety'. This formulation was used to guide intervention and ensure that all tasks were appropriate and relevant to Anna's specific problem. This highlights the importance of a formulation-driven approach and how identifying cognitive and behavioural maintenance factors can be beneficial to patients' understanding of and engagement in therapy.

\section{Therapeutic relationship}

The therapeutic relationship has been found, consistently, to be linked with successful outcomes in psychological therapy. It is noted that Anna rated the therapeutic alliance highly, which may have affected therapy outcome, however, it is also possible that the positive outcome of therapy affected Anna's ratings of alliance.

\section{ERP}

ERP was not used in this successful treatment of OCD. While some of the tasks during therapy involved Anna exposing herself to anxiety-provoking situations without using safety-seeking behaviours, the purpose of these tasks was to explore her hypotheses about what would happen without these behaviours, rather than to facilitate habituation. Anna's self-report supports the theory that change, in this case, was driven by cognitive rather than behavioural processes.

\section{Recommendations to therapists}

While this paper describes what is likely to be standard treatment of OCD, it highlights the discrepancy between the type of therapy which is currently recommended as a result of RCTs, and routine clinical practice (described by Shafran et al. 2013). Additionally, detailed descriptions of such interventions are rarely published: RCTs tend not to describe the interventions which were used, therefore it is difficult to tell whether the mechanism for change through ERP is prolonged exposure and habituation, or a behavioural experiment testing a cognition. It is only through detailed case studies such as this, and experimental research, that the question, 'habituation or cognitive shift' will be answered. The present paper provides a comprehensive depiction of treatment of intrusive cognitions, of a sexual nature, and provides some evidence to support the idea that, in at least some cases of OCD, an individualized, formulation-driven approach, using behavioural experiments designed to test specific cognitions is effective. Anna reported that the most helpful aspects in the successful treatment of her OCD were cognitive methods and a shared formulation. The findings of this study present an interesting avenue for further larger scale research projects exploring the effectiveness of individualized, formulation-driven, CBT; as well as a case example for clinicians who are concerned about high drop-out rates in ERP.

\section{Appendix}

Anna's scores on routine IAPT therapy outcome measures. Pre-therapy measures were taken as part of a CBT for anxiety group, although this did not target Anna's OCD cognitions specifically, and she continued to seek help following this group. 


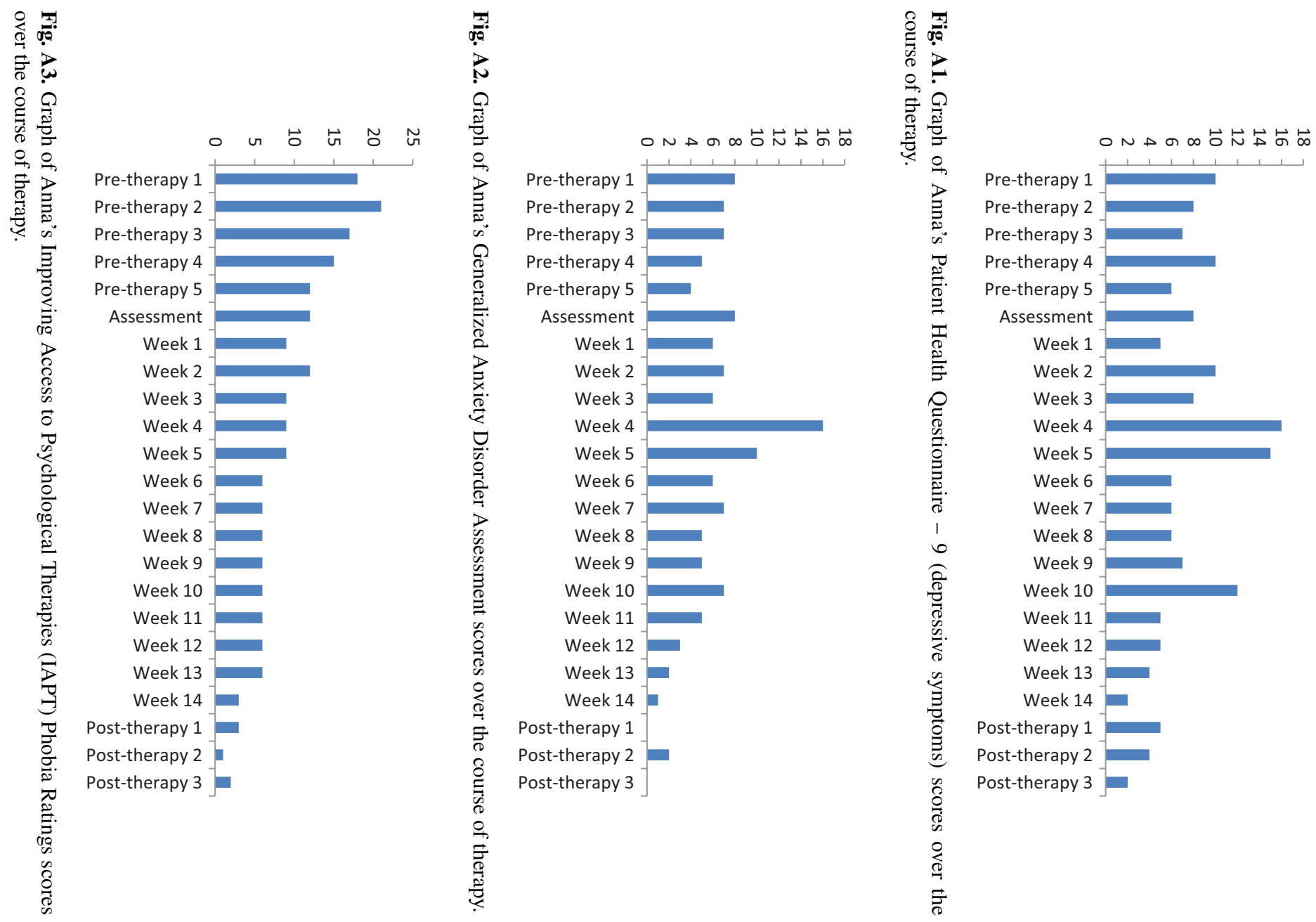




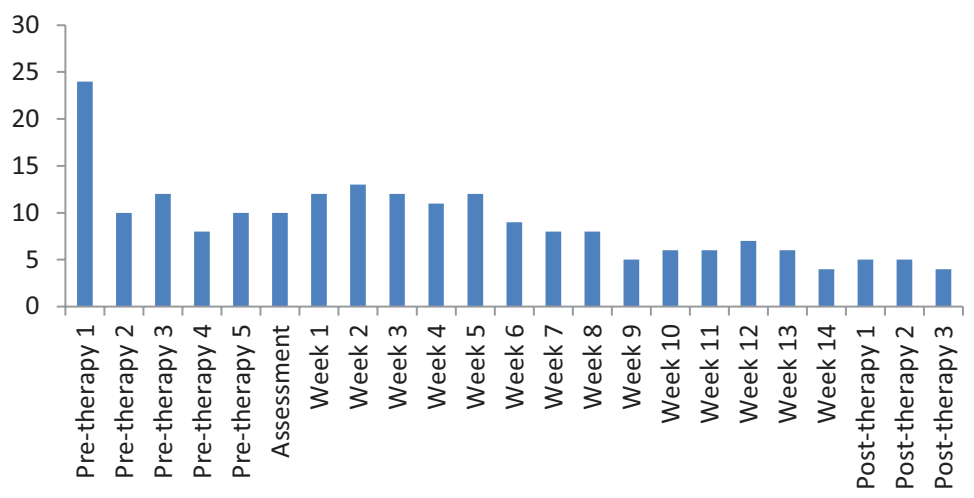

Fig. A4. Graph of Anna's Improving Access to Psychological Therapies (IAPT) Work and Social Adjustment scores over the course of therapy.

Appendix Table A1. Anna's ratings on the Working Alliance Inventory

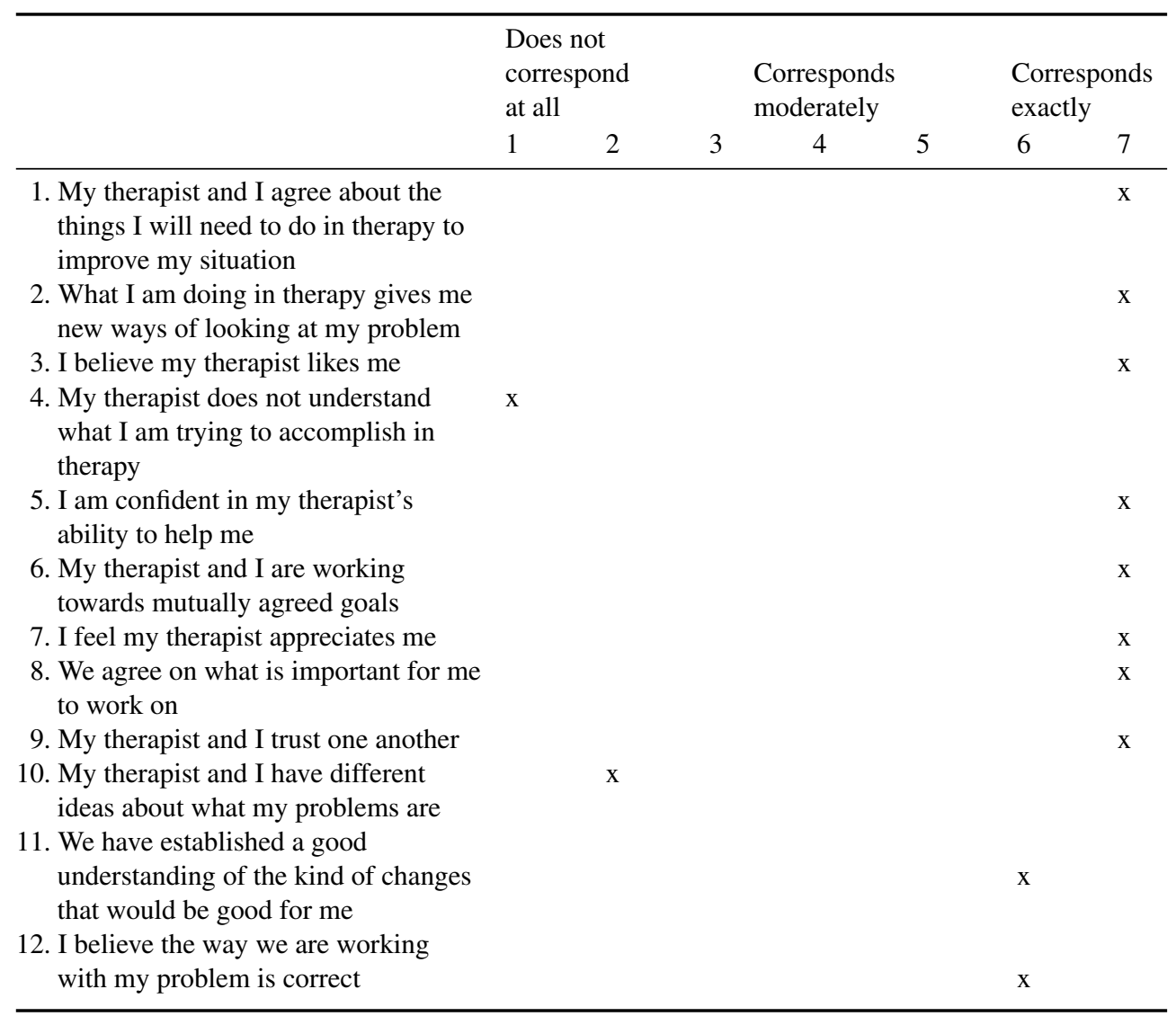




\section{Acknowledgements}

The authors thank Anna (pseudonym) for consenting to the publication of this article.

\section{Declaration of Interest}

None.

\section{Recommended follow-up reading}

Bennet-Levy J, Butler G, Fennell M, Hackmann A, Mueller M, Westbrook D (eds) (2004). Oxford Guide to Behavioural Experiments in Cognitive Therapy. Oxford: Oxford University Press.

Rachman SJ (2003). The Treatment of Obsessions. New York: Oxford University Press.

Salkovskis PM (1985). Obsessional-compulsive problems: a cognitive behavioural analysis. Behaviour Research and Therapy 23, 571-583.

\section{References}

Abramowitz JS, Franklin ME, Foa EB (2002). Empirical status of cognitive behavioural therapy for obsessive-compulsive disorder: a meta-analytic review. Romanian Journal of Cognitive Behavioural Psychotherapy 2, 89-104.

APA (2000). Diagnostic and Statistical Manual of Mental Disorders, 4th edn, Text Revision (DSM-IV$T R$ ). Washington DC: American Psychiatric Association.

Clark DM (1986). Cognitive therapy for anxiety. Behavioural Psychotherapy 14, 283-294.

Clark DM, Wells A (1995). A cognitive model of social phobia. In: Social Phobia: Diagnosis, Assessment, and Treatment (ed. R. G. Heimbery, M. R. Liebowitz, D. A. Hope and F. R. Schneier), pp. 69-93. New York: Guilford Press

Cornelissen PL, Hancock PJB, Kiviniemi V, George HR, Tovee MJ (2009). Patterns of eye movements when male and female observers judge female attractiveness, body fat and waist-to-hip ratio. Evolution and Human Behaviour 30, 417-428.

Daniels J, Wearden AJ (2011). Socialization to the model: the active component in the therapeutic alliance? A preliminary study. Behavioural and Cognitive Psychotherapy 39, 221227.

Darwin C (1955). The Expression of the Emotions in Man and Animals. New York, NY: Philosophical Library.

Dollard J, Miller NE (1950). Personality and Psychotherapy: An Analysis in Terms of Learning, Thinking and Culture. New York: McGraw-Hill.

Drummond LM, Pillay A, Kolb PJ, Fogg R, Jones-Thomas E, Rani S (2008). Community model in treating obsessive-compulsive and body dysmorphic disorders. The Psychiatrist 32, 336-340.

Foa EB, Kozak MJ (1986). Emotional processing of fear: exposure to corrective information. American Journal of Psychiatry 152, 90-96.

Foa EB, Kozak MJ, Salkovskis PM, Coles ME, Amir N (1998). The validation of a new obsessive compulsive disorder scale: The Obsessive Compulsive Inventory (OCI). Psychological Assessment 10, 206-214.

Foa EB, Liebowitz MR, Kozak MJ, Davies S, Campeas R, Franklin ME, Huppert JD, Kjernisted K, Rowna V, Schmidt AB, Blair Simpson H, Tu X (2005). Randomised, placebo-controlled trial of exposure and response prevention, clomipramine, and their combination in the treatment of obsessivecompulsive disorder. American Journal of Psychiatry 162, 151-161. 
Franklin ME, Foa EB (1998). Cognitive behavioural treatments for obsessive compulsive disorder. In: A Guide to Treatments That Work (ed. P. E. Nathan and J. M. Gorman), pp. 339-357. New York: Oxford University Press.

Horvarth AO, Greenberg LS (1989). Development and validation of the Working Alliance Inventory. Journal of Counselling Psychology 36, 223-233.

Jonsson H, Hougaard E (2009). Group cognitive behavioural therapy for obsessive compulsive disorder: a systematic review and meta-analysis. Acta Psychiatrica Scandinavica 119, 98-106.

Keijsers GPJ, Schaap CPDR, Hoogduin CAL (2000). The impact of interpersonal patient and therapist behaviour in cognitive behaviour therapy: a review of empirical studies. Behaviour Modification 24, 264-297.

Kroenke K, Spitzer RL, Williams JBW (2001). The PHQ-9: validity of a brief depression severity measure. Journal of General Internal Medicine 16, 606- 613.

LeDoux J (1998). The Emotional Brain. London: Phoenix.

Llewelyn SP (1988). Psychological therapy as viewed by clients and therapists. British Journal of Clinical Psychology 27, 223-237.

Marks I (1986). Behavioural Psychotherapy. Bristol: John Wright.

Martin DJ, Garske JP, Davis MK (2000). Relation of the therapeutic alliance with outcome and other variables: a meta-analytic review. Journal of Consulting and Clinical Psychology 68, 438450.

Mundt J, Marks I, Shear MK, Greist JM (2002). The work and social adjustment scale: a simple measure of impairment in functioning. British Journal of Psychiatry 180, 461-464.

NICE (2005). Obsessive compulsive disorder: core interventions in the treatment of obsessive compulsive disorder and body dysmorphic disorder. London: National Institute for Health and Clinical Excellence.

Obsessive Compulsive Cognitions Working Group (1997). Cognition assessment of obsessivecompulsive disorder. Behaviour Research and Therapy 35, 667-681.

Polman A, Bouman TK, van Hout WJPJ, de Jong PJ, den Boer JA (2010). Processes of change in cognitive-behavioural treatment of obsessive compulsive disorder: current status and some future directions. Clinical Psychology and Psychotherapy 17, 1-12.

Ponniah K, Magiati I, Hollon SD (2013). An update on the efficacy of psychological therapies in the treatment of obsessive-compulsive disorder in adults. Journal of Obsessive-Compulsive Related Disorders 2, 207-218.

Purdon C (2004). Empirical investigations of thought suppression in OCD. Journal of Behavior Therapy and Experimental Psychiatry 35, 121-136.

Rachman SJ (1997). A cognitive theory of obsessions. Behaviour Research and Therapy 35, 793-802.

Rachman SJ (1998). A cognitive theory of obsessions: elaborations. Behaviour Research and Therapy 36, 385-401.

Rachman SJ (2003). The treatment of obsessions. New York (NY): Oxford University Press.

Rachman SJ, DeSilva P (1978). Abnormal and normal obsessions. Behaviour Research and Therapy 16, 233-238.

Radomsky AS, Shafran R, Coughtrey AE, Rachman S (2010). Cognitive behaviour therapy for compulsive checking in OCD. Cognitive and Behavioural Practice 17, 119-131.

Rogers CR (1957). The necessary and sufficient conditions of therapeutic personality change. Journal of Consulting Psychology 21, 95-103.

Salkovskis PM (1991). The importance of behaviour in the maintenance of anxiety and panic: a cognitive account. Behavioural Psychotherapy 19, 6-19.

Salkovskis PM (1985). Obsessional-compulsive problems: a cognitive behavioural analysis. Behaviour Research and Therapy 23, 571-583.

Salkovskis PM (1989). Cognitive-behavioural factors and the persistence of intrusive thoughts in obsessional problems. Behaviour Research and Therapy 27, 677-682. 
Salkovskis PM, Shafran R, Rachman SJ, Freeston MH (1999). Multiple pathways to inflated responsibility beliefs in obsessional problems: Possible origins and implications for therapy and research. Behaviour Research and Therapy 37, 1055-1072.

Shafran R, Radomsky AS, Coughtrey AE, Rachman S (2013). Advances in the cognitive behavioural treatment of obsessive compulsive disorder. Cognitive Behaviour Therapy 42, 265-274.

Spitzer RL, Kroenke K, Williams JBW, Lowe B (2006). A brief measure for assessing generalised anxiety disorder: the GAD-7. Archives of Internal Medicine 166, 1092-1097.

Wegner DM, Schneider DJ, Carter SR, White TL (1987). Paradoxical effects of thought suppression. Journal of Personality and Social Psychology 53, 5-13.

Wells A (1997). Cognitive Therapy of Anxiety Disorders: A Practice Manual and Conceptual Guide. Chichester, UK: Wiley.

Wells A (2000). Emotional Disorders and Metacognition: Innovative Cognitive Therapy. Chichester: John Wiley \& Sons.

Wilhelm S (2001). Obsessive-compulsive disorder. In Empirically Supported Cognitive Therapies: Current and Future Applications (ed. W. J. Lyddon and J. V. Jones Jr.), pp. 118-133. New York, NY: Springer Publishing Co.

\section{Learning objectives}

(1) To outline the proportion of patients with OCD who refuse ERP.

(2) To draw attention to the discrepancy between clinical guidelines and clinical practice for the treatment of OCD.

(3) To highlight how individualized, formulation-driven behavioural experiments are likely to be an effective alternative.

(4) To provide a detailed case example of designing and conducting formulation-based experiments, designed to test cognitions. 